\title{
Low Cost Modification Kit for Retrofitting on Small Diesel Engines to Run on Straight Vegetable Oils
}

\author{
S. Jindal
}

\begin{abstract}
Although many varieties of vegetable oils do have characteristics similar to that of diesel, but varieties of problems are encountered on prolonged use of vegetable oils in the existing design of engines. To address these problems, transesterification is found to be the best, but, it has its own problems and can not be adopted at rural sites. To run the engines directly with straight vegetable oils, suitable modification in the engine is required. A low cost modification kit is developed for retrofitting on small power agricultural diesel engines. Once the kit is fitted on the engine, it can easily substitute upto $60 \%$ of diesel with vegetable oils of local origin. The engine delivers comparable power, efficiency and lower emissions of unburnt hydrocarbons, carbon monoxide and smoke and runs smoothly without effect on life.
\end{abstract}

Index Terms—Diesel engine, modification kit, vegetable oil.

\section{INTRODUCTION}

Many varieties of vegetable oils do have characteristics similar to that of diesel derived from petroleum crude and can be used directly as fuel in diesel engines. But varieties of problems are encountered on prolonged use of vegetable oils in the existing design of engines. The problems encountered in the existing design of the engine while working with vegetable oil are mainly greater load on the fuel pump and injector due to higher viscosity; filter clogging and difficult filtration; difficult cold starting due to residual oil in the combustion chamber; and vegetable oil's reaction with fuel line material.

To address these problems and for reducing the viscosity of vegetable oils, different strategies suggested are: Pyrolysis; Dilution; Microemulsion; and, Transesterification. Out of these, transesterification is mostly adopted as it gives the matching properties with that of diesel and hence can be used without many modifications in the existing engine [1]. But, the chemistry of transesterification requires careful and precise working which is normally not possible at local level at user end and hence commercial and logistic loading of prices leaves the same unfeasible.

With the major research effort dedicated to the area of biodiesel, a small number of researchers are advocating the extension of Rudolph Diesel's concept of neat vegetable oil as CI engine fuel. Schrimpff [2] compared straight vegetable oil (SVO) with Bio-diesel (BD) on the issues of production,

Manuscript received December 14, 2013; revised May 20, 2014. This work was supported in part by the Petroleum Conservation Research Association (PCRA).

S. Jindal is with the College of Technology and Engineering, Maharana Pratap University of Agriculture and Technology, Udaipur, India (e-mail: sjindals@gmail.com). environmental effects and economic aspects and concluded that SVO outweigh BD due to problems of conversion at small level production, higher toxicity and comparatively poor bio-degradability, and poor social acceptability. Also the regional availability of SVO puts it in better acceptance when logistics requirement for $\mathrm{BD}$ are high. Thus it would be highly desirable, if the vegetable/plant oils can directly be used without any processing or chemical modification as in biodiesel. Then, the SVOs can be used in rural areas and elsewhere also, thus reducing the dependence on petroleum diesel to that extent.

Jones and Peterson concluded, on the basis of long term tests, that straight waste oils (SWO) blends above 20 percent nearly always result in engine damage or maintenance problems [3]. Many other researchers have been involved in testing programs designed to evaluate long term performance characteristics. Results of these studies indicated that potential problems such as stuck piston rings, carbon buildup on injectors, fuel system failure, and lubricating oil contamination existed when vegetable oils were used as alternative fuels [4]. Engine tests showed that carbon deposits in the engine were reduced if the oil was heated prior to combustion. It was also noted that carbon deposit levels differed for oils with similar viscosities, indicating that oil composition was also an important factor.

Schlautman et al. supplied soybean oil and diesel blend (75: 25 ) in a naturally aspirated direct injection engine to observe the contamination of lubrication oil and carbon deposits [5]. They found that the power output was at par for blend and diesel. Viscosity and temperature of the lubricating oil along with the temperature of coolant increased sharply with the use of blend as compared to the diesel. The increase in the temperature of exhaust gas was observed after long duration. The compression pressure reduced with elapsed time. Also abnormal carbon deposits were noticed on internal parts (injectors, valve heads, etc.).

According to Calaise and Clarke, the main problem is that vegetable oil is much more viscous (thicker) than conventional diesel fuel [6]. It must be heated (thinned) so that it can be properly atomized by the fuel injectors. If it's not properly atomized, it won't burn properly, forming deposits on the injectors and in the cylinder head, leading to poor performance, higher emissions, and reduced engine life.

The problems associated with the use of crude vegetable oils in diesel engines have been discussed by Barsic and Humke [7], Ziejewski and Kaufman [8], Goering and Fry [9] and Kaufman et al. [10]. The main conclusion from these researchers is that coking is a potentially serious problem with unmodified vegetable oil fuels.

McDonnell et al. used the blends of semi refined oil (SRO) from rapeseed and diesel in test engines to establish the 
suitability of non-esterified oils in diesel engines [11]. It was concluded that SRO can be used as a diesel fuel extender in unmodified direct injection (DI) diesel engines. The only practical difference observed was that the injector requires more frequent servicing which could be easily accepted looking to the cost advantage of SRO over rapeseed methyl ester (RME).

Lee et al. studied the effect of fuel properties (density, surface tension, viscosity, etc.) on the atomization in a high pressure chamber and concluded that (i) the higher density leads to greater penetration with narrow angle as compared to light oil where gas phase of fuel was distributed widely around the injector tip and (ii) with lower values of density, surface tension and viscosity, more atomization and mixture formation were promoted [12]. Tate et al. verified that the density of biodiesel shows a linearly decreasing trend with increase in temperature [13].

Final Report of 'Advanced Combustion Research for Energy from Vegetable Oils (ACREVO)' project to study the burning characteristics of vegetable oil droplets under high pressure and high temperature conditions contains many experimental findings [14]. One finding states that due to high stability of rapeseed oil at high temperatures, it is possible to preheat the oil up to $150^{\circ} \mathrm{C}$ where it attains the same viscosity as the diesel oil and its atomization is comparable with diesel fuel. Further it has been established that an addition of $9 \%$ of ethyl alcohol $(95 \%)$ brings a great benefit regarding the pre-heating oil temperature. The presence of alcohol allows a reduction in the inlet temperature of oil from $150^{\circ} \mathrm{C}$ to $80^{\circ} \mathrm{C}$ and the combustion produces less soot.

To make use of these strategies with maximum substitution of diesel without much hassle at user end, an approach of combining the dilution with preheating is investigated in this study. D. Agarwal and A. K. Agarwal have shown that the preheated Jatropha oil can be used successfully for running a diesel engine without damage to the engine [15]. Still, pure vegetable oil, when used in engine, tends to stick in the system on shutting down the engine and creates problem in cold starting. Thus, it is necessary to flush the system before shutting down.

Looking to the large number of the small powered engines employed in agricultural applications world over, a low cost modification kit is developed for, and tested on, a $3.5 \mathrm{~kW}$ single cylinder, water cooled engine, normally employed for agricultural application. The modification kit makes use of engine exhaust to heat the vegetable oil-diesel blend and employs a dual fuel system with extra fuel filters to take care of cold starting and filter clogging problems. It can be retrofitted on the existing engines by a mechanic on site with normal tool kit and very little effort. With modification kit, the engine can run with pure diesel or on a blend of vegetable oil-diesel.

Once the kit is fitted on the engine, it can easily substitute upto $60 \%$ of diesel with vegetable oils of local origin. The engine delivers comparable power, efficiency and lower emissions of unburnt hydrocarbons, carbon monoxide and smoke and runs smoothly without effect on life. With locally extracted oils, the cost of engine operation is lowered to a great extent and the savings can pay back the cost of kit on nominal hours of engine use.

\section{MODIFICATION KIT}

The schematic arrangement of components of the modification kit is given in Fig. 1. It consists of a heat exchanger, additional fuel tank, a filtration unit, few valves and tubes, fittings, etc.

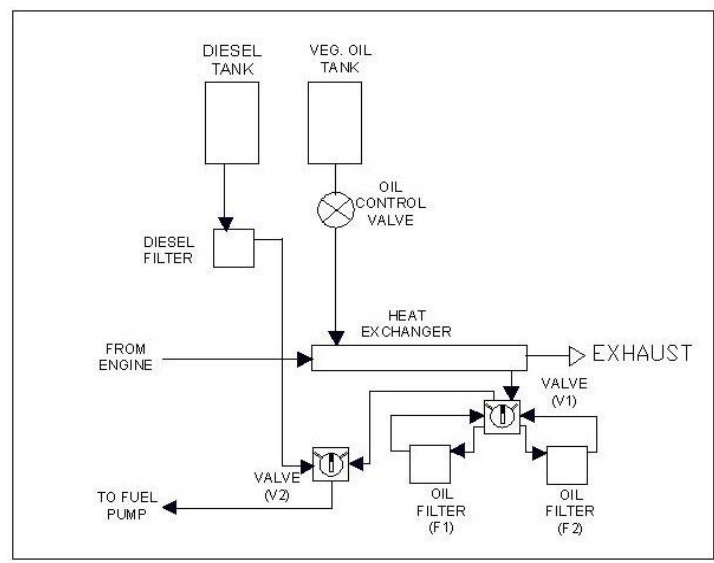

Fig. 1. Schematic arrangement of modification kit.

\section{A. Viscosity Reduction}

The viscosity of these oils can be easily reduced to acceptable levels by preheating the oils to a temperature above $80^{\circ} \mathrm{C}$ (as seen from the studies). Putting up an extra source of heat for preheating is not possible in remote locations and also it will increase the operating cost of the system. The engine exhaust, which is normally leaving the engine above $200^{\circ} \mathrm{C}$, is utilized to heat the oil before filtration. A heat exchanger is designed and fabricated for maximum fuel flow condition (at full load) and is mounted on exhaust manifold before silencer. The added advantage is reduction in temperature of exhaust gases leaving the system to atmosphere.

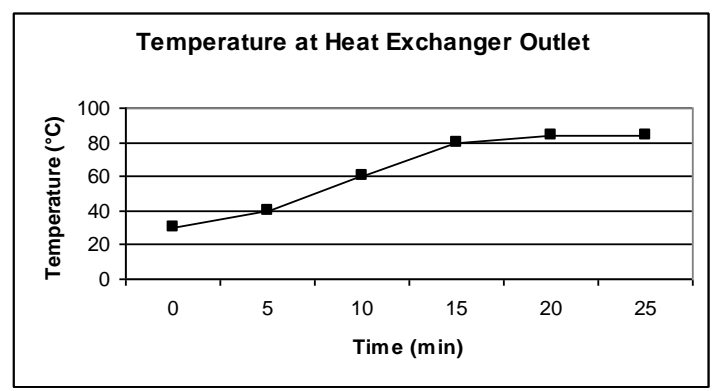

Fig. 2. Temperature obtained with Heat exchanger.

To save on the losses, the heat exchanger is insulated with asbestos rope and a plaster of paris coating over it. In addition to the two ports for inlet and outlet of vegetable oil, one port is provided in bottom for draining the oil when not in use and another on top for fitting one pressure relief valve for safety. The material selected for the fabrication of this heat exchanger is common MS pipes and a tube-in-tube design is adopted for ease in fabrication and cleaning. The heat exchanger is provided on one end with a nipple with external threads fitting into the existing exhaust manifold of the engine and a socket at other end for mounting the silencer. The ports are mounted with MS nipples, to which fuel pipes can be connected. The oil in the heat exchanger reaches to a 
temperature of $60{ }^{\circ} \mathrm{C}$ within 10 minutes (Fig. 2) and to $80{ }^{\circ} \mathrm{C}$ within 15 minutes from ambient temperature $\left(27^{\circ} \mathrm{C}\right)$.

\section{B. Cold Starting}

It is difficult to start the engine from cold with vegetable oils as the flash point of these oils is higher than that of the diesel. Also, when stopping the engine, some fuel remains inside the combustion chamber in liquid form. The gum present in vegetable oils can stick with the piston rings making these sticky causing difficulties in engine startup.

This issue is resolved by adopting a strategy of using dual fuel (in serial manner), i.e., the engine should start with diesel, after sufficient temperature is reached and vegetable oil gets heated upto the required temperature in the heat exchanger, the engine should be switched over to run on heated vegetable oil for rest of the operation. Again, when the engine is to be stopped, it is switched back on diesel and then stopped so that the fuel pump, injector and cylinder space is flushed off with diesel and there is no any residual vegetable oil left in the system. For this, an additional frame is designed and mounted for holding another fuel tank to carry the vegetable oil at a level higher than the existing diesel fuel tank to ensure smooth gravity flow of vegetable oil through the heat exchanger and filters (Fig. 3b). The fuel lines are rerouted through the valve arrangement in filtration unit to control the flow path as per requirement.

SVO tank is placed above diesel tank with clearance for ease of pouring (6" to 7" inches). The structure is held in place with existing diesel tank stand studs in cylinder block of the engine. The SVO tanks stand is fitted on this structure over which tank is placed rigidly. The structure comprises of two 5 $\mathrm{mm}$ thick plates of $125 \mathrm{~mm}$ width and $500 \mathrm{~mm}$ length welded together.

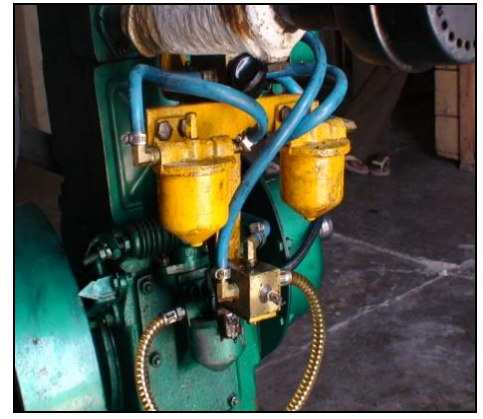

(a) Filter unit in position

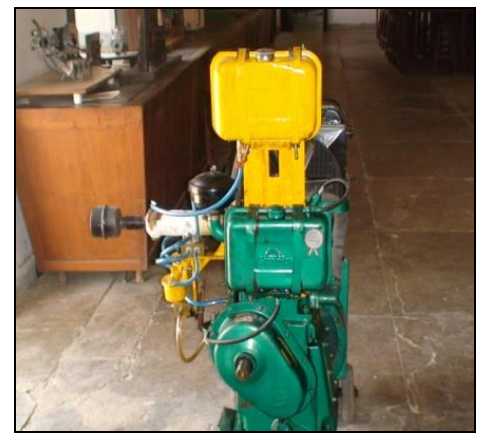

(b) Tank stand in position with SVO tank

Fig. 3. Components of modification kit.

\section{Filtration}

Due to high gum contents and higher viscosity of the oils, the fuel filter gets clogged frequently and engine starts starving for fuel. For cleaning of the filter, engine need to be stopped creating a break in its service. To take care of this problem, a filtration unit is designed for vegetable oils which can be mounted on the engine itself to provide alternating flow path. A set of two filters with flow control valve (Valve-I) is mounted on a specially designed frame which is mounted on the engine in the space above fuel pump (Fig. 3a). The arrangement permits toggling between two alternative paths through two filters such that only one filter remains in line at a time and other one is free for cleaning. This system also helps in toggling between diesel and vegetable oil through second valve (Valve-II). The diesel line filter is not disturbed. The valve arrangement is designed in such a way that, if one wants to run engine on diesel only, the vegetable oil lines can be cut-off easily (Fig. 1).

Being acidic in nature, vegetable oils react with copper based alloys like brass, etc., and hence both the valves are made from M.S. square bar of size $50 \mathrm{~mm}$ and are fitted with polypropylene oil seals to prevent leakage and the ports are fitted with M.S. nipples for pipe fitting.

Before running the engine on vegetable oil, it is required that the engine should run with diesel fuel for at least 10 minutes in winters and 5 minutes in summers. After initial warming of the engine and when vegetable oil's temperature has reached more than $60^{\circ} \mathrm{C}$ in heat exchanger, the engine can be made to run on vegetable oil blend. Before shutting down the engine, again the engine should be made to run on diesel fuel for about 4-5 minutes.

\section{RESULTS AND DISCUSSIONS}

\section{A. Performance}

Different blends of vegetable oil and diesel were prepared and tested for optimizing the highest blend ratio. The blends were tested in the engine for evaluation of performance and emissions. It is observed that blends upto $60 \%$ (vegetable oil $-60 \%$ ) works well delivering comparable performance (Fig. 4). With Jatropha oil blends, near full load conditions, the brake thermal efficiency (BTE) was highest with diesel (27.76\%) followed by $20 \%$ and $40 \%$ blend. With $80 \%$ and above blending, the thermal efficiency decreases by $18 \%$. Similarly, the brake specific fuel consumption (BSFC) is lowest for diesel (29.38 kg/kW-h) due to lower mass density and higher calorific value, followed by $20 \%$ and $40 \%$ blends (31.06 kg/kW-h). With pure Jatropha oil, the thermal efficiency is observed as $22.96 \%$ and specific fuel consumption as $38.56 \mathrm{~kg} / \mathrm{kW}$-h at full load.

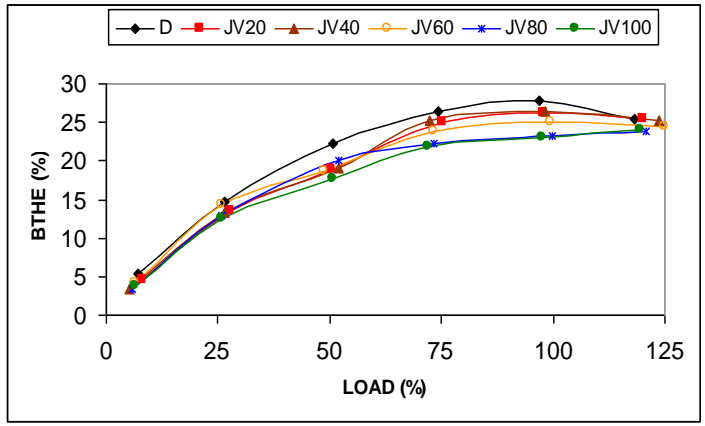

a). Brake thermal efficiency. 

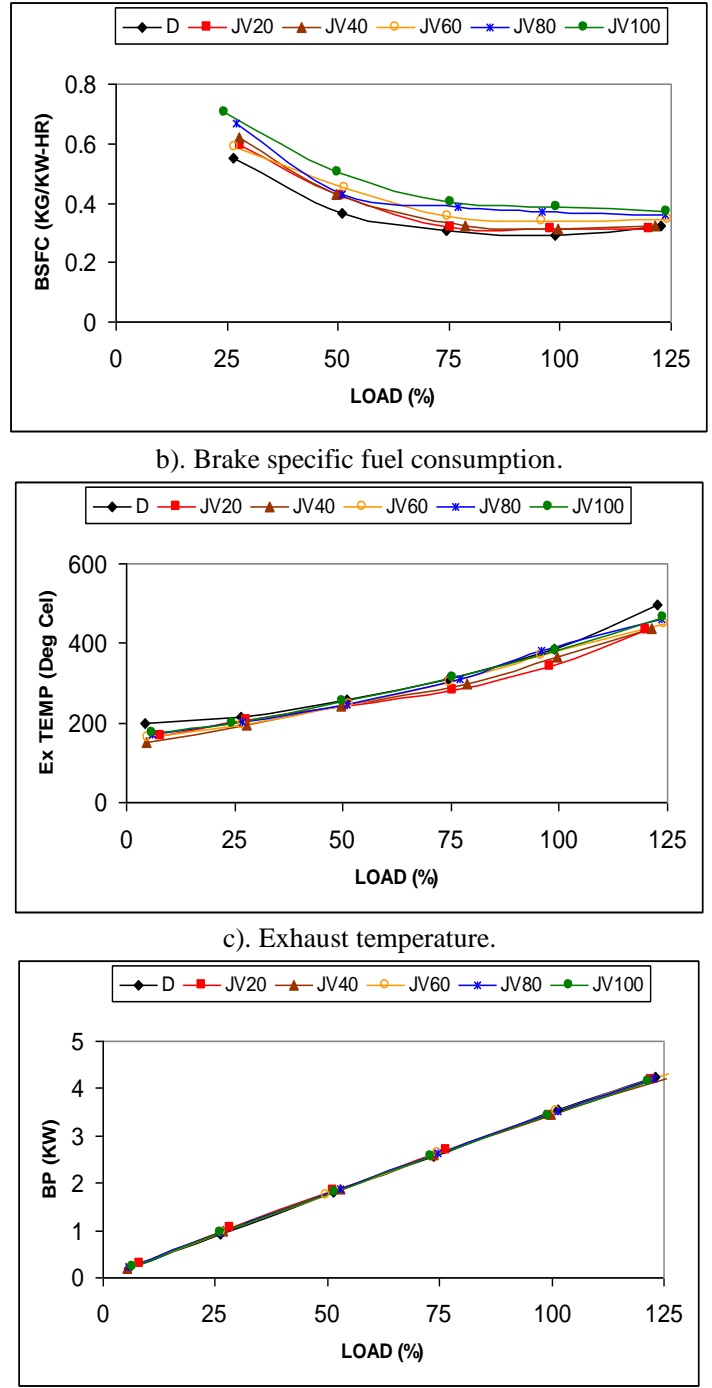

d). Brake power.

Fig. 4. Comparison of engine performance with Jatropha oil blends.

The exhaust temperature and mean effective pressure were highest for pure Jatropha oil resulting in higher indicated power (6.88 $\mathrm{kW}$ against $5.77 \mathrm{~kW}$ developed by diesel). As higher blends require more pumping work due to higher viscosity, the increase in indicated power is offset and the brake power delivered remains same for all blends.

The blends developed higher cylinder pressures as compared to diesel but rate of pressure rise and net heat release rate is comparable with diesel only upto a blend ratio of $60 \%$ with Jatropha oil blends. The cumulative heat release rates are found higher for higher blends and advancement of peak heat release rates is observed due to earlier admission of fuel.

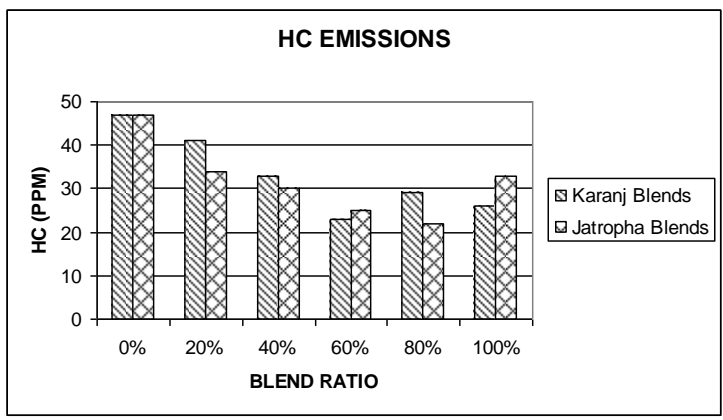

a). HC emissions
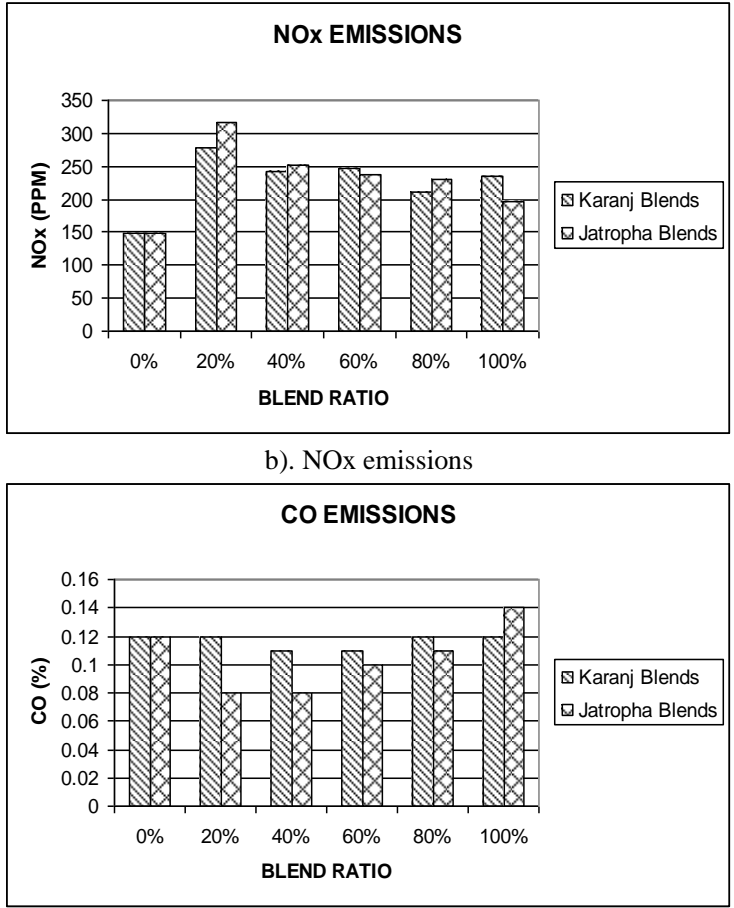

c). $\mathrm{CO}$ emissions

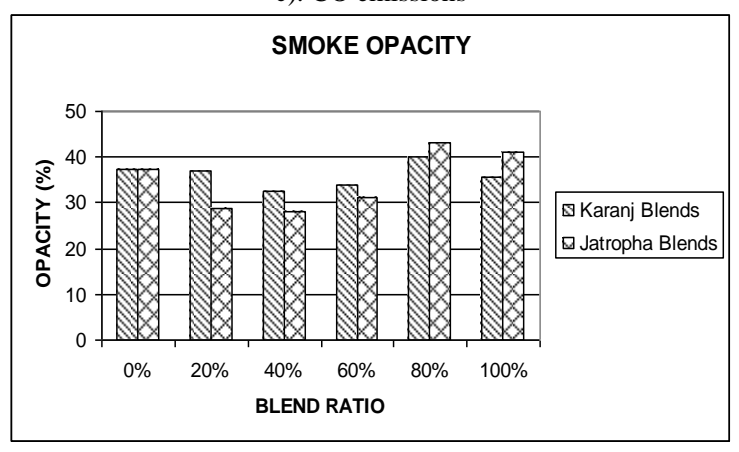

d). Smoke emissions

Fig. 5. Comparison of engine emissions with diesel and oil blends.

\section{B. Emissions}

The emissions with blends are shown in Fig. 5. Hydrocarbon emissions are found to decrease with increase in oil in the blends upto $60 \%$ after which it increases. The NOx emissions increase by $100 \%$ for $20 \%$ blend but start decreasing on increasing the oil contents of the blend. Carbon monoxide and smoke emission with blends tend to decrease upto $40 \%$ after which it starts increasing whereas $\mathrm{CO} 2$ emissions remains almost same for all blends.

\section{CONCLUSION}

The low cost Modification Kit developed for small power $(3.5 \mathrm{~kW})$ diesel engines, mostly being used for agricultural applications, can be retrofitted easily at rural sites. The engine can make use of locally available vegetable oils as fuel partially substituting the petro diesel. The cost of operation can be reduced drastically if oils extracted at local points from the seeds collected by farmers and their family members are put to use. The kit takes care of cold starting and filter clogging problems. With kit mounted on engine, the engine delivers comparable power and fuel efficiency with vegetable oil blends. The harmful emissions are also reduced. 


\section{REFERENCES}

[1] R. Altin, S. Cetinkaya, and H. S. Yucesu, "The potential of using vegetable oil fuels as fuel for diesel engines," Energy Conversion and Management, vol. 42, pp. 529-538, 2001.

[2] E. Schrimpff, "Biodiesel or pure plant oil inquiry into the better fuel strategy," A White Paper at University of Applied Sciences, D-85350, Freising, Germany.

[3] S. Jones and C. L. Peterson, "Using unmodified vegetable oils as a diesel fuel extender - A literature review," Department of Biological and Agricultural Engineering, University of Idaho, Moscow, Idaho 83843, Feb 2007.

[4] G. L. Pratt, "Sunflower oil for fuel," North Dakota Farm Research, vol. 38, no. 2, pp. 22-23, 1980.

[5] N. J. Schlautman, J. Schinstock, and M. A. Hanna, "Unrefined expelled soybean oil performance in a diesel engine," Transaction of $A S A E$, vol. 29, pp. 70-73, 1986.

[6] P. Calais and A. R. Clark, "Vegetable oil as a diesel replacement fuel," Environmental Science, 2007.

[7] N. J. Barsic and A. L. Humke, "Performance and emission characteristics of a naturally aspirated diesel engine with vegetable oil fuels," Society of Automotive Engineers, vol. 810262, pp. 95-109, 1981.

[8] M. Ziejewski and K. R. Kaufman, "Laboratory endurance test of a sunflower oil blend in a diesel engine," Journal of the American Oil Chemists Society, vol. 60, no. 8, pp. 1567-1573, 1983.

[9] C. E. Goering and B. Fry, "Engine durability screening test of a diesel oil/soy oil/ alcohol micro emulsion fuel oil," Journal of the American Oil Chemists Society, vol. 61, no. 10, pp. 1627-1632, 1984.

[10] K. R. Kaufman, M. Ziejewski, G. L. Pratt, and H. J. Goettler. "Fuel injection anomalies observed during long term engine performance tests on alternative fuels," Society of Automotive Engineers, vol. 852089, pp. 591-600, 1985.

[11] K. P. McDonnel, S. M. Ward, P. B. McNulty, and H. R. Howard, "Results of engine and vehicle testing of semi refined rapeseed oil," Transaction of ASAE, vol. 43, no. 3, p. 1309, 2000.
[12] S. W. Lee, D. Tanaka, J. Kusakaand, and Y. Daisho, "Effects of diesel fuel characteristics on spray and combustion in a diesel engine," JSAE Review, vol. 23, pp. 407-414, 2002.

[13] R. E. Tate, K. C. Watts, C. A. W. Allen, and K. I. Wilkie, "The densities of three biodiesel fuels at temperatures up to $300 \mathrm{degC}$," Fuel 85, pp. 1004-1009, 2006.

[14] Final Report, "Advanced combustion research for energy from vegetable oils (ACREVO)," Project Co-Ordinated by the Laboratoire de Combustion et Systemes Reactifs, Orleans, France, 2007.

[15] D. Agarwal and A. K. Agarwal, "Performance and emissions characteristics of Jatropha oil (preheated and blends) in a direct injection compression ignition engine," Applied Thermal Engineering, vol. 27, pp. 2314-2323, 2007.

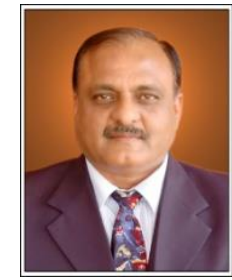

S. Jindal obtained his bachelor and master degrees with honors in mechanical engineering from M.B.M. Engineering College, Jodhpur, Rajasthan, India, and doctoral degree in mechanical engineering from College of Technology and Engineering, Udaipur, India. He did master degree in business administration from Faculty of Management Studies, Sukhadia University, Udaipur, India.

$\mathrm{He}$ is presently serving as a professor and the head of Mechanical Engineering Department and Coordinator of Centre for Technology Management at College of Technology and Engineering, Udaipur, Rajasthan, India. His research interest is in energy and thermal engineering with main emphasis on alternative fuels for internal combustion engines, renewable energy, energy management and audit and clean development mechanism (CDM).

Prof. Jindal has contributed many papers on alternative fuels, energy conservation and renewable energy harnessing in international/national journals and conferences. He is a life member of Institution of Engineers (India), life member of Indian Society of Mechanical Engineers, and Senior life member of Indian Institution of Industrial Engineering. 